\title{
RED FLAGS, TASK SPESIFIC KNOWLEDGE DAN BEBAN KERJA PADA KEMAMPUAN AUDITOR DALAM MENDETEKSI FRAUD
}

\author{
Muzdalifah \\ Email: muzdalifah@stiem-bongaya.ac.id \\ Prodi Akuntansi STIEM Bongaya \\ Jalan Letjen Pol.A.Mappaodang No. 28 Makassar. \\ Nur Syamsu \\ Email:nursyamsu@stiem-bongaya.ac.id \\ Prodi Manajemen STIEM Bongaya \\ Jalan Letjen Pol.A.Mappaodang No. 28 Makassar.
}

\begin{abstract}
ABSTRAK
Penelitian ini bertujuan membuktikan Red Flags, task specific knowledge dan beban kerja berpengaruh terhadap kemampuan mendeteksi fraud yang dilakukan oleh auditor. pendekatan kuantitatif dengan data primer melalui kuesioner yang langsung disebarkan. pada sampel. Auditor Kantor Akuntan Publik (KAP) di Makassar sebagai populasi dan peneli menentukan sampel dengan teknik purposive sampling yakni 52 orang auditor yang telah bekerja sebagai auditor minimal tiga tahun karena dianggap telah memiliki pengalaman dan pengetahuan yang cukup tinggi untuk dapat mendeteksi fraud. Desain penelitian regresi linier berganda. Hasil penelitian membuktikan red flag dan task spesifik knowledge positif signifikan memengaruhi kemampuan auditor mendeteksi fraud, sedangkan beban kerja tidak signifikan memengaruhi kemampuan auditor mendeteksi fraud.
\end{abstract}

Kata Kunci: red flag, task spesifik knowledge, beban kerja, kemampuan auditor mendeteksi fraud

\section{ABSTRACT}

This study aims to prove that Red Flags, task specific knowledge and workload affect the ability to detect fraud committed by auditors. Quantitative approach with primary data through a questionnaire that is distributed directly. on the sample. The auditors of the Public Accounting Firm (KAP) in Makassar as a population and researchers determined the sample by purposive sampling technique, namely 52 auditors who have worked as auditors for at least three years because they are considered to have sufficient experience and knowledge to be able to detect fraud. Multiple linear regression research design. The research results prove that red flag and specific task knowledge have a significant positive effect on the ability of auditors to detect fraud, while workload does not significantly affect the ability of auditors to detect fraud.

Keyword : Red Flags, task specific knowledge, workload, detect fraud committed by auditors 


\section{PENDAHULUAN}

Maraknya berita di surat kabar dan televisi akhir-akhir ini yang melibatkan kantor akuntan publik membuat masyarakat mulai meragukan kemampuan auditor dalam mencegah ke curangan atau fraud. Fraud merupakan perbuatan tindakan menyesatkan yang sengaja dilakukan berupa penipuan atau menyesatkan pihak lain yang dapat membuat salah saji material saat pemeriksaan. (Arens, Elder, \& Beasley, 2010).

Kasus kecurangan Kantor Akuntan Publik yang pernah terjadi di Indonesia dilakukan oleh KAP Marlinna dan Melyiana Syamsul (2017) dengan belum menemukan bukti audit yang cukup dan akurat atas akun piutang pembiayaan konsumen dan menyelesaikan melaksanakan proses terkait deteksi risiko fraud beserta pengakuannya.

Kasus kecurangan KAP tersebut menyebabkan publik mulai mempertanyakan kapasitas auditor dalam mengaudit. Publik mulai mempertanyakan kemampuan auditor mengumpulkan bukti-bukti audit yang relevan yang menyebabkan kegagalan dalam mendeteksi kecurangan. Seorang auditor dapat mendeteksi kecurangan (fraud) dalam laporan keuangan sesuai dengan standar aturan yang berlaku saat ini (Jefri \& Mediaty, 2014). Kemampuan auditor dalam mendeteksi fraud merupakan kompetensi dan keahlian yang dimiliki auditor sehingga dapat membaca pemicu terjadinya kecurangan (Anggriawan \& Ferry, 2014). Namun, kenyataan yang terjadi dalam memeriksa, seorang auditor seringkali sulit membedakan antara kesalahan (error) dengan kecurangan.

Beberapa aspek yang berperan dalam mendeteksi kecurangan yaitu red flags. Red flags menjadi sinyal jika terjadi sesuatu yang aneh dalam pemeriksaan perusahaan dan dijadikan acuan dalam menyelidiki lebih lanjut keanehan tersebut dan pihak yang terkait dengan hal tersebut. Hasil Penelitian (Sandi P, 2015), (Prasetyo, 2015) dan (Rahim, Muslim, \& Amin, 2019) membuktikan red flags signifikan menjelaskan kemampuan auditor mendeteksi adanya kecurangan. Semakin tinggi tingkat red flags yang ditemukan oleh auditor, maka semakin tinggi pula kemampuannya dalam mendeteksi fraud.

Untuk dapat mengenal indikasi fraud, diperlukan pengetahuan yang memadai dari seorang auditor dan ini tidaklah mudah. Specific knowledge dibutuhkan seorang auditor 
agar dapat menyelesaikan tugas-tugasnya secara spesifik atau terinci yang didapat melalui pelatihan dan pengalamannya dalam mengivestigasi kecurangan. (Yusrianti, 2015) dan (Kusumawaty \& Betri, 2019) menemukan bahwa task specific knowledge signifikan memengaruhi pendeteksian auditor atas fraud laporan keuangan.

Ketika kerjaan yang dimiliki auditor tidak sebanding dengan waktu dan kemampuannya maka akan terjadi beban kerja (Ulfa, 2015). Kelelahan yang disebabkan oleh beban kerja yang banyak memicu tindakan dysfunctional audit behavior (penyimpangan di luar standar audit) sehingga kemampuan auditor mendeteksi fraud dapat berkurang (Nasution \& Fitriany, 2012). Hasil penelitian yang dilakukan (Kusumawaty \& Betri, 2019) menemukan beban kerja signifikan berpengaruh terhadap kemampuan auditor dalam mendeteksi fraud. Namun, hasil penelitian (Sari \& Helmayunita, 2018) meenmukan bahwa beban kerja negatif sinifikan berpengaruh terhadap kemampuan auditor mendeteksi kecurangan.

Penelitian ini merujuk penelitian yang dilakukan oleh (Purwanti \& Astika, 2017) yang meneliti tentang pengaruh auditor's professional skepticism, red flags dan beban kerja pada kemampuan auditor dalam mendeteksi fraud. Tujuan penelitian ini ingin membuktikan Red Flags, task specific knowledge dan beban kerja berpengaruh terhadap kemampuan mendeteksi fraud yang dilakukan oleh auditor.

\section{Teori Disonansi Kognitif}

Teori disonansi kognitif membentuk perubahan sikap auditor dalam meramalkan niat dalam rangka untuk mengurangi ketidaksesuaian atau disonansi yang terjadi. Unsur kognitif memberikan pemahaman kepada auditor agar opini yang dikeluarkan setelah memeriksa harus sesuai dengan bukti-bukti audit di sekitar tempat pemeriksaan.

Teori disonansi kognitif dalam penelitian ini digunakan untuk menjelaskan pengaruh interaksi antara Red Flags, task specific knowledge terhadap kemampuan Auditor dalam mendeteksi fraud.

\section{Hipotesis}

Hipotesis penelitian ini yaitu :

H1 : Red Flags positif signifikan memengaruhi kemampuan auditor mendeteksi fraud. 
H2 : Task Spesifik Knowledge positif signifikan memengaruhi kemampuan auditor mendeteksi fraud.

H3 : Beban kerja negatif signifikan memengaruhi kemampuan auditor mendeteksi fraud.

\section{METODE PENELITIAN}

Untuk menjawab hipotesis yang diajukan dalam penelitian ini maka digunakan pendekatan kuantitatif dengan data primer melalui kuesioner yang langsung disebarkan. pada sampel. Auditor Kantor Akuntan Publik (KAP) di Makassar sebagai populasi dan peneli menentukan sampel dengan teknik purposive sampling yakni 52 orang auditor yang telah bekerja sebagai auditor minimal tiga tahun karena dianggap telah memiliki pengalaman dan pengetahuan yang cukup tinggi untuk dapat mendeteksi fraud. Persamaan regresi linier berganda penelitian ini :

$$
\begin{aligned}
\mathrm{Y}= & \mathrm{a}+\beta_{1} \mathrm{X}_{1}+\beta_{2} \mathrm{X}_{2}+\beta_{3} \mathrm{X}_{3}+\mathrm{e} \\
& \text { Keterangan : } \\
& \mathrm{X}_{1}=\text { Red Flags } \\
& \mathrm{X}_{2}=\text { Task specific konwledge } \\
& \mathrm{X}_{3}=\text { Beban kerja } \\
& \mathrm{Y}=\text { Kemampuan Auditor dalam Mencegah Fraud } \\
& \mathrm{a}=\text { Bilangan Konstanta } \\
& \beta=\text { Koefisien Regresi }
\end{aligned}
$$

\section{Definisi Operasional dan Pengukuran Variabel}

Definisi operasional variabel yang digunakan dalam penelitian ini dapat dilihat sebagai berikut :

1) Red Flags

Red flags ialah sebuah tanda tindak kecurangan dari suatu entitas yang harus dicegah oleh Auditor saat melakukan audit. Indikator Red Flags dalam penelitian ini yaitu : 1) Memahami karakteristik tekanan, 2) Informasi audit, 3) Pengawasan manajemen, 4) Transaksi yang tidak biasa dan 5) Sistem informasi dan akuntansi. 
2) Task Spesific Knowledge

Task Spesific Knowledge adalah pertimbangan yang diambil auditor setelah menemukan informasi baik dari fakta, konsep, dan pengamatan dari lingkungan sekitarnya terkait penyelesaian tugasnya. Indikator Task Spesific Knowledge dalam penelitian ini yaitu : 1) pemahaman pada proses audit, 2) kapasitas auditor dalam merevisi penilaiannya pada fraud.

3) Beban kerja

Beban kerja adalah menumpuknya kerjaan auditor dari klien yang diperiksanya dalam proses audit. Indikator beban kerja dalam penelitian ini yaitu : 1) Jumlah penugasan audit, 2) waktu pengauditan, 3) Besarnya tugas dan tanggungjawab menurut hukum, 4) pembatasan lingkup tugas audit.

4) Kemampuan auditor dalam mendeteksi fraud.

Kemampuan auditor mendeteksi fraud yakni kapasitas yang dimiliki auditor dalam menangkap sinyal terjadinya fraud pada klien yang menggunakan jasa pemeriksanaanya. Indikator kemampuan auditor dalam mendeteksi fraud dalam penelitian ini yaitu : 1) traning pencegahan dan pendeteksian fraud, 2) mereview secara berkala dibagian keuangan, 3) mereview pengendalian internal, 4) faktor penyebab fraud, 5) Sistem dan prosedur audit.

Variabel penelitian ini diukur dengan skala likert lima point dari sangat tidak setuju (1), tidak setuju (2), kurang setuju (3), setuju (4), sangat setuju (5).

\section{Hasil}

\section{HASIL DAN PEMBAHASAN}

\section{Hasil Uji Normalitas}




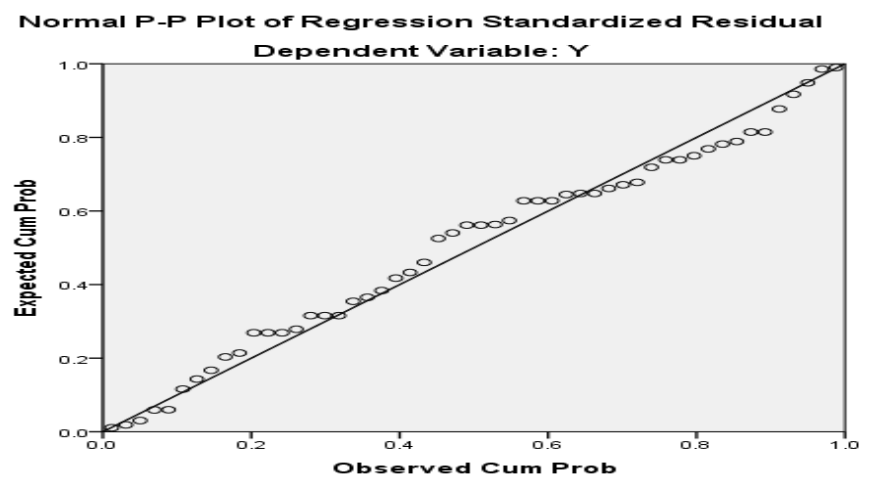

Gambar 1. Hasil Uji Normalitas

Sumber : Data Diolah SPSS V. 23.00 (2020)

Ouput grafik normal P-Plot, menunjukkan bahwa data dalam penelitian layak digunakan dan dikatakan normal.

\section{Hasil Uji Multikolinearitas}

Pengujian multikolinearitas penelitian ini menunjukkan persamaan dapat ditoleransi dan keberadaannya tidak mengganggu model dengan nilai Varians Inflating Factors (VIF) variabel bebas yaitu : red flags sebesar 3,357, task specific knowledge sebesar 3,358 dan beban kerja sebesar 1,500, ketiga variabel bebas penelitian ini juga mempunyai nilai VIF lebih kecil dari 10 dan nilai toleransinya lebih besar dari 0,1, dapat dilhat pada tabel berikut:

Tabel 1. Hasil Uji Multikolinearitas

\begin{tabular}{|c|c|c|c|}
\hline \multirow{2}{*}{ Model } & & \multicolumn{2}{|c|}{ Collinearity Statistics } \\
\hline & & Tolerance & VIF \\
\hline \multirow{4}{*}{1} & (Constant) & & \\
\hline & $\mathrm{X} 1$ & 268 & 3,726 \\
\hline & $\mathrm{X} 2$ & ,272 & 3,674 \\
\hline & $\mathrm{X} 3$ & ,942 & 1,062 \\
\hline
\end{tabular}

\section{Hasil Koefisien Determinasi}




\begin{tabular}{lllll}
1 & $.936^{\mathrm{a}}$ & .876 & .868 & .20111 \\
\hline
\end{tabular}

a. Predictors: (Constant), X3, X2, X1

b. Dependent Variable: Y

Sumber : Data diolah SPSS V.23.00 (2020)

Output di atas menunjukan nilai $\mathrm{R}$ square $\left(\mathrm{R}^{2}\right)$ yang diperoleh adalah 0,876 atau 87,60\% menjelaskan kemampuan Auditor dalam mendeteksi Fraud dipengaruhi oleh red flag, task spesific knowledge dan beban kerja.

\section{Hasil Pengujian Hipotesis}

Tabel 3. Hasil Uji Parsial (Uji t)

\begin{tabular}{|c|c|c|c|c|c|c|}
\hline \multirow[t]{2}{*}{ Mode } & & \multicolumn{2}{|c|}{ Unstandardized Coefficients } & \multirow{2}{*}{$\begin{array}{c}\begin{array}{c}\text { Standardized } \\
\text { Coefficients }\end{array} \\
\text { Beta }\end{array}$} & \multirow[t]{2}{*}{$\mathrm{t}$} & \multirow[t]{2}{*}{ Sig. } \\
\hline & & B & Std. Error & & & \\
\hline \multirow{4}{*}{1} & (Constant) & -.006 & .556 & & -.010 & .992 \\
\hline & $\mathrm{X} 1$ & 610 & .140 & .428 & 4.359 & .000 \\
\hline & $\mathrm{X} 2$ & .533 & .099 & .522 & 5.360 & .000 \\
\hline & $\mathrm{X} 3$ & -.137 & .091 & -.079 & -1.502 & .140 \\
\hline
\end{tabular}

a. Dependent Variable: Y

Sumber : Data diolah SPSS V.23.00 (2020)

Kemampuan Auditor dalam Mendeteksi Fraud = -0,006+ 0,610X1 + 0,533X2 - 0,137X3 + e

Persamaan di atas menjelaskan bahwa :

1. Koefisien variabel red flag dengan arah positif sebesar 0,610 yang berarti bahwa jika terjadi peningkatan red flag, maka kemampuan auditor dalam mendeteksi fraud akan meningkat sebesar 0,610 .

2. Koefisien variabel task spesific knowledge dengan arah positif sebesar 0,533 yang berarti bahwa jika terjadi peningkatan red flag maka kemampuan auditor dalam mendeteksi fraud akan meningkat sebesar 0,533.

3. Koefisien variabel beban kerja dengan arah negatif sebesar 0,137 yang berarti bahwa jika terjadi peningkatan beban kerja maka kemampuan auditor dalam mendeteksi fraud akan menurun sebesar 0,282 .

\section{Pembahasan}

Pengaruh red flag terhadap kemampuan Auditor dalam mendeteksi Fraud 
Hasil penelitian ini membuktikan hipotesis 1 yang diajukan terbukti bahwa red flag positif signifikan memengaruhi kemampuan Auditor dalam mendeteksi Fraud. Hasil ini memberi arti jika auditor mampu menemukan red flags saat memeriksa laporan keuangan klien maka kapasitasnya dalam mendeteksi fraud semakin bagus karena red flags akan memudahkan seorang auditor dalam mengambil tindakan pencegahan atas fraud yang ditemukan secepatnya.

Hasil Penelitian (Sandi P, 2015), (Prasetyo, 2015) dan (Rahim, Muslim, \& Amin, 2019) membuktikan red flags signifikan menjelaskan kemampuan auditor mendeteksi adanya kecurangan.

\section{Pengaruh task Spesific Knowledge terhadap kemampuan Auditor dalam mendeteksi}

\section{Fraud}

Hasil penelitian ini membuktikan hipotesis 2 yang diajukan terbukti bahwa task Spesific Knowledge positif signifikan memengaruhi kemampuan Auditor dalam mendeteksi Fraud. Hasil tersebut menunjukkan bahwa task Spesific Knowledge yang dimiliki oleh seorang auditor yang memadai akan membuat auditor mudah menangkap sinyal fraud. Knowledge auditor tidak hanya didapat dari pendidikan formal tetapi dari pengalaman selama mengaudit. Makin banyak kasus audit yang telah diperiksa dan penyelesaiannya akan menambah penguasaannya dalam memeriksa.

Hasil penelitian mendukung penelitian yang dilakukan oleh Yusrianti (2015) dan (Kusumawaty \& Betri, 2019) yang menemukan bahwa task Spesific Knowledge berpengaruh positif terhadap pendeteksian auditor tas fraud laporan keuangan auditor.

\section{Pengaruh beban kerja terhadap kemampuan Auditor dalam mendeteksi Fraud}

Hasil penelitian ini tidak dapat membuktikan hipotesis 3 yang diajukan bahwa beban kerja negatif tidak signifikan memengaruhi kemampuan Auditor dalam mendeteksi Fraud. Hasil penelitian ini mengandung arti beban kerja yang menumpuk tidak boleh dijadikan sebagai dalih oleh seorang auditor tidak dapat mendeteksi fraud karena seorang auditor harus memiliki profesionalitas kerja sesuai aturan dan seorang auditor dituntut harus bekerja sesuai bukti yang ada dalam laporan klien sehingga ketika ada sesuayi yang dirasakan tidak wajar maka kecurangan tersebut harus dideteksi dengan cepat. 
Hasil penelitian (Ulfa, 2015) dan (Kamaliah \& Safitri, 2017) yang menemukan bahwa beban kerja tidak memengaruhi deteksi kecurangan auditor mendukung temuan penelitian ini. Namun, hasil penelitian ini tidak sama dengan hasil penelitian (Purwanti \& Astika, 2017) dan (Sari \& Helmayunita, 2018) yang menunjukkan bahwa beban kerja sinifikan negatif berdampak pada kemampuan auditor mendeteksi kecurangan,

\section{KESIMPULAN}

Hasil penelitian membuktikan red flag dan task spesifik knowledge positif signifikan memengaruhi kemampuan auditor mendeteksi fraud, sedangkan beban kerja tidak signifikan memengaruhi kemampuan auditor mendeteksi fraud.

\section{DAFTAR PUSTAKA}

Anggriawan, \& Ferry, E. (2014). Pengaruh Pengalaman Kerja, Skeptisme Profesional dan Tekanan Waktu Terhadap Kemampuan Auditor dalam Mendeteksi Fraud. Jurnal Nasional, 3(2), 102-113.

Arens, A. A., Elder, R. J., \& Beasley, M. S. (2010). Auditing and Assurance Services (13th ed.). Upper Sadle River. New Jersey: Perason Edication Inc.

Biksa, I. A., \& Wiratmaja, I. N. (2016, Agustus). Pengaruh Pengalaman, Independensi, Skeptisme Profesional Auditor Pada Pendeteksian Kecurangan. E-Jurnal Akuntansi Universitas Udayana, 17(3), 2384-2415.

Jefri, R., \& Mediaty, M. (2014). Pendeteksian Kecurangan (Fraud) Laporan Keuangan. Jurnal Akuntansi STIE Muhammadiyah Palopo, 1(2).

Kamaliah, V. D., \& Safitri, D. (2017). PENGARUH BEBAN KERJA, PELATIHAN DAN TEKANAN WAKTU TERHADAP KEMAMPUAN AUDITOR DALAM MENDETEKSI KECURANGAN (Studi Empiris BPK RI Perwakilan Provinsi Riau). JOM Fekon Universitas Riau, 4(1).

Kusumawaty, M., \& Betri, B. (2019). Pengaruh Pengalaman Audit, Beban Kerja, Task Specific Knowledge, Tipe Kepribadian Terhadap Pendeteksian Kecurangan Laporan Keuangan (Studi Kasus Kantor Akuntan Publik Kota Palembang). Balance. Jurnal Akuntansi dan Bisnis, 4(1).

Nasution, H., \& Fitriany. (2012). Pengaruh Beban Kerja, Pengalaman Audit dan Tipe Kepribadian Terhadap Skeptisme Profesional dan Kemampuan Auditor dalam Mendeteksi Kecurangan. Jurnal\&Prosiding SNA, 15, 1-23.

Novianti.S. (2008). Skeptisme Profesional Auditor Dalam Mendeteksi Kecurangan. Jurnal Akuntansi dan Keuangan Indonesia, 5(1), 102-125. 
Prasetyo, S. (2015). Pengaruh Red Flags, Skeptisme Profesional Auditor, Kompetensi, Independensi, dan Profesionalisme Terhadap Kemampuan Auditor dalam Mendeteksi Kecurangan. JOM Fekon, 2(1), 2-10.

Pratama, N. A., Sukarmanto, E., \& Purnamasari, P. (2019). Pengaruh Red Flags dan Whistleblowingsystem terhadap Kemampuan Auditor dalam Mendeteksi Kecurangan (Fraud) (Studi Empiris pada BUMN di Kota Bandung). Spesia (Seminar Penelitian Sivitas Akademika UNISBA), 5(1). Bandung.

Purwanti, I. P., \& Astika, I. P. (2017). Pengaruh Auditor's Profesional Skepticism, Red Flags, Beban kerja Pada Kemampuan Auditi. e-Jurnal Universitas Udayana, 1(2).

Rahim, S., Muslim, M., \& Amin, A. (2019, Januari). Red Flag And Auditor Experience Toward Criminal Detection Trough Profesional Skepticism. Jurnal Akuntansi UNTAR, XXIII(1), 47-62.

Sandi P. (2015). Pengaruh Red Flags, Skeptisme Profesional Auditor, Kompetensi, Independensi, Dan Profesionalisme Terhadap Kemampuan Auditor Dalam Mendeteksi Kecurangan (Studi Empiris Pada Kantor Akuntan Publik Di Pekan Baru, Padang, Dan Medan Yang Terdaftar Di IAPI 2013). JOM Fekon, 2(1), 1-15.

Sari, Y. E., \& Helmayunita, N. (2018). Pengaruh Beban Kerja, Pengalaman, dan Skeptisme Profesional Terhadap Kemampuan Auditor Dalam Mendeteksi Kecurangan (Studi Empiris pada BPK RI Perwakilan Propinsi Sumatera Barat). Wahana Riset Akuntansi, 6(1).

Sugiyono. (2015). Metode Penelitian (Metode Kuantitatif, Kualitatif, R\&D). . Bandung: Alfabeta.

Ulfa, N. (2015). Pengaruh Pengalaman, Beban Kerja, dan Pelatihan Terhadap Skeptisme dan Kemampuan Auditor Mendeteksi Kecurangan. JOM Fekon, 2(1), 2-11.

Umri, C., Islahuddin, \& Nadirsyah. (2015). Pengaruh Sikap Skeptisisme Profesional Auditor , Bukti Audit Kompeten Dan Tekanan Waktu Terhadap Pendeteksian Kecurangan. Jurnal Magister Akuntansi, 4(1), 20-28.

Yusrianti, H. (2015, Maret). Pengaruh Pengalaman Audit, Beban Kerja, Task Specific Knowledge Terhadap Pendeteksian Kecurangan Laporan Keuangan (Studi pada KAP di Sumatera Bagian Selatan). Jurnal Manajemen dan Bisnis Sriwijaya, 13(1). 